\title{
Erratum to: Genome-wide transcriptome and proteome analyses of tobacco psaA and $p s b A$ deletion mutants
}

\author{
Sadhu Leelavathi - Amit Bhardwaj - Saravanan Kumar - Abhishek Dass • \\ Ranjana Pathak $\cdot$ Shiv S. Pandey $\cdot$ Baishnab C. Tripathy $\cdot$ K. V. Padmalatha \\ Gurusamy Dhandapani · Mogilicherla Kanakachari • Amolkumar Uddhaorao Solanke • \\ Polumetla Ananda Kumar • Rino Cella • V. Siva Reddy
}

Published online: 11 March 2011

(C) Springer Science+Business Media B.V. 2011

\section{Erratum to: Plant Mol Biol}

DOI 10.1007/s11103-011-9731-y

Due to an unfortunate turn of events, one author's name was omitted in the original publication. The correct representation of the authors and their affiliations are listed above and below and should be treated as definitive by the reader.

The online version of the original article can be found under doi:10.1007/s11103-011-9731-y.

S. Leelavathi · A. Bhardwaj · S. Kumar · A. Dass

R. Pathak · V. Siva Reddy $(\bowtie)$

Plant Transformation Group, International Center for Genetic

Engineering and Biotechnology, Aruna Asaf Ali Marg,

New Delhi 110067, India

e-mail: vsreddy@icgeb.res.in

S. S. Pandey - B. C. Tripathy

School of Life Sciences, Jawaharlal Nehru University,

New Delhi 110067, India

K. V. Padmalatha - G. Dhandapani - M. Kanakachari ·

A. U. Solanke - P. A. Kumar

National Research Centre on Plant Biotechnology, Indian

Agricultural Research Institute, PUSA campus,

New Delhi 110012, India

R. Cella

Dipartimento di Genetica e Microbiologia, Università di Pavia,

Via Ferrata 1, 27100 Pavia, Italy 